\title{
Second-Order Delay Differential Equations to Deal the Experimentation of Internet of Industrial Things via Haar Wavelet Approach
}

\author{
Yongtao Xuan $\mathbb{D}^{1},{ }^{1}$ Rohul Amin $\mathbb{D}^{2},{ }^{2}$ Fakhar Zaman, ${ }^{2}$ Zohaib Khan, ${ }^{2}$ Imad Ullah, \\ and Shah Nazir $\mathbb{D}^{3}$ \\ ${ }^{1}$ Guangdong University of Science and Technology, Dongguan City, 523083 Guangdong Province, China \\ ${ }^{2}$ Department of Mathematics, University of Peshawar, Peshawar 25120, Pakistan \\ ${ }^{3}$ Department of Computer Science, University of Swabi, Ambar 23430, Pakistan \\ Correspondence should be addressed to Yongtao Xuan; xyt0512@126.com and Shah Nazir; shahnazir@uoswabi.edu.pk
}

Received 25 January 2021; Revised 24 February 2021; Accepted 20 March 2021; Published 7 April 2021

Academic Editor: Rahim Khan

Copyright (c) 2021 Yongtao Xuan et al. This is an open access article distributed under the Creative Commons Attribution License, which permits unrestricted use, distribution, and reproduction in any medium, provided the original work is properly cited.

\begin{abstract}
In this article, an efficient numerical approach for the solution of second-order delay differential equations to deal with the experimentation of the Internet of Industrial Things (IIoT) is presented. With the help of the Haar wavelet technique, the considered problem is transformed into a system of algebraic equations which is then solved for the required results by using Gauss elimination algorithm. Some numerical examples for convergence of the proposed technique are taken from the literature. Maximum absolute and root mean square errors are calculated for various collocation points. The results show that the Haar wavelet method is an effective method for solving delay differential equations of second order. The convergence rate is also measured for various collocation points, which is almost equal to 2 .
\end{abstract}

\section{Introduction}

Delay differential equations (DDEs) are type of DEs in which the solution of the unknown function is given in the previous time interval. A system whose performance does not depend directly on time is a time-invariant delay system. This systems can be defined by constant coefficients of the $n$th order ordinary DEs [1]. DDEs are used for modelling of various phenomenon such as modelling of systems with memory, electric circuits, and mechanical systems. The application of these systems in population dynamics [2] can be used in communication networks, mass transportation, remote controls, and biological systems. Many of the processes, both natural and artificial, in medicine, chemistry, engineering, economics, etc. involve time delays. The Internet of Things (IoT) contributes in facilitating the needs of daily life such as IoT for healthcare using effects of Mobile computing [3] and nonlinear delay integro-differential equations for wireless sensor network and IoT [4].
There are numerous approaches available in the literature for the solution DDEs of second order. Seong and Majid [1] developed the Adams Moulton technique to solve the second-order DDEs. Ibrahim [5], used 2h-step Spline method to solve the DDEs. Sedaghat [2], utilized the Chebyshev polynomials method to find the solution of DDEs. Ehigie et al. [6] implement a 3-point block technique to solve DDEs of second order. Chebyshev wavelet technique was developed by Ghasemi and Kajan [7] to solve the DDEs. Ahmad et al. [8] solved the DDEs by a block hybrid method. Multistep methods was used by Okunuga and Ehigie [9] to solve the DDEs. Brown [10] used a method of implicit multistep to solve the DDEs. Ismail et al. [11] found the solution of DDEs by 3-point block methods. Ehigie et al. [12] used a method of 2-step continuous linear multistep to solve the second-order DDEs. Some other well-known methods are the following: Runge-Kutta [13], Shift Walsh matrix method [14], Hermite interpolation method [15], method of retarded initial value problems [16], one-step collocation method [17], 
coupled block technique [18], one-step block techniques [11], implicit block technique [19], Direct integration implicit variable method [19], predictor-corrector method [20], Taylor method [21], fuzzy mapping and control method [22], variational iteration method [23, 24], and Galerkin method [25]. A structure for the IIoT cloud-fog hybrid network for industry data processing was proposed by Liu et al. [26]. Sahal et al. [27] studied the strong point and flaws of open source technologies for big data. Khan et al. [28] offered the idea of IIoT in a novel manner for supporting readers to comprehend the IIoT. Gulati and Kaur [29] analysed the main opportunities assimilated from the idea of IoT into industry with suggesting reference architecture.
The use of Haar wavelet have wide-ranging applications in scientific computing. The Haar Collocation Technique (HCT) is used for fractional Riccati type differential equations [30], Birthmark based identification [31], delay Fredholm-Volterra integral equations [32], delay integrodifferential equations [4], systems of fractional differential equations [33], and fractional integrodifferential equations [34] in recent literature. This article studies the solutions of second-order DDEs, that is, we develop numerical technique using Haar wavelet with constant delay.

In this paper, we discuss the solution of the second-order DDEs using a HCT to deal with the experimentation of IIoT, consider linear DDEs as

$$
\left(\begin{array}{l}
w^{\prime \prime}(t)=a(t) w^{\prime}(t)+b(t) w(t)+c(t) u(t)+d(t) w(t-\tau)+e(t) u(t-\tau) \\
w^{\prime}(0)=\alpha_{1}, w(0)=\alpha_{2} \\
w(t)=\phi(t),-\tau \leq t<0
\end{array}\right.
$$

where $u(t)$ is a control function, $\phi(t)$ is the delay condition, and $w(t)$ is a state function.

The paper is organized as some basic results and notions are given in Section 2. Section 3 provides the HCT solution for linear DDEs of second order. In Section 4, the HCT validation is given. The results are discussed in Section 5, and the conclusion is given in the last part of the paper.

\section{Haar Wavelet}

Scaling function on $\left[\alpha_{1}, \alpha_{2}\right)$ is [35]

$$
h_{1}(p)=\left(\begin{array}{ll}
1 & \text { for } p \in\left[\alpha_{1}, \alpha_{2}\right), \\
0 & \text { elsewhere. }
\end{array}\right.
$$

Mother wavelet on $\left[\alpha_{1}, \alpha_{2}\right)$ is

$$
h_{2}(p)=\left(\begin{array}{ll}
1 & \text { for } p \in\left[\alpha_{1}, \frac{\alpha_{1}+\alpha_{2}}{2}\right) \\
-1 & \text { for } p \in\left[\frac{\alpha_{1}+\alpha_{2}}{2}, \alpha_{2}\right) \\
0 & \text { elsewhere. }
\end{array}\right.
$$

The other terms can be written as

$$
h_{i}(p)=\left(\begin{array}{ll}
1 & \text { for } t \in\left[\eta_{1}, \eta_{2}\right) \\
-1 & \text { for } t \in\left[\eta_{2}, \eta_{3}\right) \\
0 & \text { elsewhere }
\end{array}\right.
$$

where $\eta_{1}=\alpha_{1}+\left(\alpha_{2}-\alpha_{1}\right)(\zeta / d), \eta_{2}=\alpha_{1}+\left(\alpha_{2}-\alpha_{1}\right)(\zeta+0.5 /$ $d), \eta_{3}=\alpha_{1}+\left(\alpha_{2}-\alpha_{1}\right)(\zeta+1 / d)$, where $d=2^{r}$, and $\zeta=0,1$, $\cdots, d-1$. The number $i$ can be calculated as $i=d+\zeta+1$. If we take interval $[0,1]$, then values of $\eta_{1}, \eta_{2}$, and $\eta_{3}$ are: $\eta_{1}=$ $\zeta / d, \eta_{2}=1 / 2+\zeta / d, \eta_{3}=1+\zeta / d$. Any member in $L^{2}[0,1)$, is $u(p)=\sum_{k=1}^{\infty} \lambda_{k} h_{k}(t)$, we truncate this series is $u(t) \approx \sum_{k=1}^{N} \lambda_{k}$ $h_{k}(t)$. Let

$$
\begin{aligned}
p_{i, 1}(t) & =\int_{0}^{t} h_{i}(x) d x, \\
P_{i, 1}(p) & =\left(\begin{array}{ll}
p-\eta_{1} & \text { for } p \in\left[\eta_{1}, \eta_{2}\right), \\
\eta_{3}-p & \text { for } p \in\left[\eta_{2}, \eta_{3}\right), \\
0 & \text { elsewhere. }
\end{array}\right.
\end{aligned}
$$

Also, $p_{i, 2}$ is

$$
p_{i, 2}(p)=\int_{0}^{p} p_{\mathrm{i}, 1}(r) d r
$$

We obtain

$$
P_{i, 2}(p)=\left(\begin{array}{ll}
\frac{1}{2}\left(p-\eta_{1}\right)^{2} & \text { if } p \in\left[\eta_{1}, \eta_{2}\right), \\
\frac{1}{4 m^{2}}-\frac{1}{2}\left(\eta_{3}-p\right)^{2} & \text { if } p \in\left[\eta_{2}, \eta_{3}\right) \\
\frac{1}{4 m^{2}} & \text { if } p \in\left[\eta_{3}, 1\right) \\
0 & \text { elsewhere. }
\end{array}\right.
$$

Generally,

$$
P_{i, n}(p)=\int_{0}^{p} P_{i, n-1}(r) d r
$$


Thus, [9],

$$
P_{i, n}(t)=\left(\begin{array}{ll}
0 & \text { if } t \in\left[0, \eta_{1}\right), \\
\frac{\left(t-\eta_{1}\right)^{n}}{n !} & \text { if } t \in\left[\eta_{1}, \eta_{2}\right), \\
\frac{\left[\left(t-\eta_{1}\right)^{n}-2\left(\eta_{1}-\eta_{2}\right)^{n}\right]}{n !} & \text { if } t \in\left[\eta_{2}, \eta_{3}\right), \\
\frac{1}{n !}\left[\left(t-\eta_{1}\right)^{n}-2\left(\eta_{1}-\eta_{2}\right)^{n}+\left(t-\eta_{3}\right)^{n}\right], & \text { if } t \in\left[\eta_{3}, 1\right) .
\end{array}\right.
$$

The $\left[a_{1}, a_{2}\right]$ interval for HCT is discretized as

$$
p_{i}=a_{1}+\left(a_{2}-a_{1}\right) \frac{i-0.5}{2 M} i=1,2,3, \cdots, 2 M .
$$

The points defined in the above Eq. (10) are called collocation points (CPs).

\section{Numerical Method}

Here, we describe the proposed method for second-order DDEs to deal with the experimentation of IIoT. Let $w^{\prime \prime}(t)$ $\in L^{2}[0,1)$, then

$$
w^{\prime \prime}(t)=\sum_{i=1}^{N} \lambda_{i} h_{i}(t)
$$

Integrating Eq. (11) from 0 to $t$,

$$
w^{\prime}(t)-w^{\prime}(0)=\sum_{i=1}^{N} \lambda_{i} p_{i, 1}(t)
$$

from Eq. (1), $w^{\prime}(0)=\alpha_{1}$, so we get

$$
w^{\prime}(t)=\alpha_{1}+\sum_{i=1}^{N} \lambda_{i} p_{i, 1}(t)
$$

Now, integrating Eq. (13) from 0 to $t$, the following relation yields:

$$
w(t)-w(0)=\alpha_{1}(t)+\sum_{i=1}^{N} \lambda_{i} p_{i, 2}(t)
$$

from Eq. (1), $w(0)=\alpha_{2}$, so we have

$$
w(t)=\alpha_{2}+\alpha_{1}(t)+\sum_{i=1}^{N} \lambda_{i} p_{i, 2}(t)
$$
get

By putting Eq. (11), Eq. (13), and Eq. (15) in Eq. (1), we

$$
\begin{aligned}
\sum_{i=1}^{N} \lambda_{i} h_{i}(t)-a(t) \sum_{i=1}^{N} \lambda_{i} p_{i, 1}(t)-b(t) \sum_{i=1}^{N} \lambda_{i} p_{i, 2}(t) \\
\quad=\left(\begin{array}{l}
a(t) \alpha_{1}+b(t)\left(\alpha_{2}+\alpha_{1}(t)\right)+c(t) u(t)+d(t) \phi(t-\tau)+e(t) u(t-\tau), \text { for } t<0, \\
a(t) \alpha_{1}+b(t)\left(\alpha_{2}+\alpha_{1}(t)\right)+c(t) u(t)+d(t)\left(\alpha_{2}+\alpha_{1}(t-\tau)+\sum_{i=1}^{N} \lambda_{i} p_{i, 2}(t)(t-\tau)\right)+e(t) u(t-\tau), \text { for } t>0 .
\end{array}\right.
\end{aligned}
$$

Discretizing this Eq. (16) at $t_{j} \mathrm{CPs}$, we have

$$
\begin{aligned}
\sum_{i=1}^{N} \lambda_{i} h_{i}\left(t_{j}\right)-a\left(t_{j}\right) \sum_{i=1}^{N} \lambda_{i} p_{i, 1}\left(t_{j}\right)-b\left(t_{j}\right) \sum_{i=1}^{N} \lambda_{i} p_{i, 2}\left(t_{j}\right) \\
\quad=\left(\begin{array}{l}
a\left(t_{j}\right) \alpha_{1}+b\left(t_{j}\right)\left(\alpha_{2}+\alpha_{1}\left(t_{j}\right)\right)+c\left(t_{j}\right) u\left(t_{j}\right)+d\left(t_{j}\right) \phi\left(t_{j}-\tau\right)+e\left(t_{j}\right)\left(u\left(t_{j}\right)-\tau\right), \text { for } t_{j}<0 \\
a\left(t_{j}\right) \alpha_{1}+b\left(t_{j}\right)\left(\alpha_{2}+\alpha_{1}\left(t_{j}\right)\right)+c\left(t_{j}\right) u\left(t_{j}\right)+d\left(t_{j}\right)\left(\left(\alpha_{2}+\alpha_{1}\left(t_{j}-\tau\right)\right)+\sum_{i=1}^{N} \lambda_{i} p_{i, 2}\left(t_{j}-\tau\right)\right)+e\left(t_{j}\right) u\left(t_{j}-\tau\right), \text { for } t_{j}>0
\end{array}\right.
\end{aligned}
$$


The above system in matrix notations as given by

$$
M \lambda=B
$$

where

$$
\begin{aligned}
& M=\left[m_{i j}\right]_{N \times N}, \lambda=\left[\lambda_{j}\right]_{N \times 1}, B=\left[b_{j}\right]_{N \times 1} \text {, } \\
& b_{j}=\left(\begin{array}{l}
a\left(t_{j}\right) \alpha_{1}+b\left(t_{j}\right)\left(\alpha_{2}+\alpha_{1} t_{j}\right)+c\left(t_{j}\right) u\left(t_{j}\right)+d\left(t_{j}\right) \phi\left(t_{j}-\tau\right)+e\left(t_{j}\right) u\left(t_{j}-\tau\right) \text { for } t_{j}<0, \\
a\left(t_{j}\right) \alpha_{1}+b\left(t_{j}\right)\left(\alpha_{2}+\alpha_{1} t_{j}\right)+c\left(t_{j}\right) u\left(t_{j}\right)+d\left(t_{j}\right)\left(\alpha_{2}+\alpha_{1}\left(t_{j}-\tau\right)+e\left(t_{j}\right) u\left(t_{j}-\tau\right) \text { for } t_{j}>0,\right.
\end{array}\right. \\
& m_{i j}=\left(\begin{array}{l}
h_{i}\left(t_{j}\right)-a\left(t_{j}\right) p_{i, 1}\left(t_{j}\right)-b\left(t_{j}\right) p_{i, 2}\left(t_{j}\right) \text { for } t_{j}<0, \\
h_{i}\left(t_{j}\right)-a\left(t_{j}\right) p_{i, 1}\left(t_{j}\right)-b\left(t_{j}\right) p_{i, 2}\left(t_{j}\right)-d\left(t_{j}\right) p_{i, 2}\left(t_{j}-\tau\right) \text { for } t_{j}>0,
\end{array}\right.
\end{aligned}
$$

Hence, $\lambda_{i}$ is calculated as $\lambda=M^{-1} B$. This is a linear system of order $N \times N$, which is solved by the Gauss elimination technique. By putting these $\lambda_{i}$ 's in Eq. (15), we get the required solution of second-order DDEs defined in (1).

\section{Numerical Examples}

Let $w_{a p}$ be approximate and $w_{e x}$ is exact solution for CPs and GPs, then maximum absolute $L_{c p}$ error is $L_{c p}=\max \mid w_{e x c}-$ $w_{a p c} \mid$. The $M_{c p}$ root mean square errors at CPs is $M_{c p}=$ $\sqrt{(1 / N)\left(\Theta\left|w_{\text {exc }}-w_{a p c}\right|^{2}\right)}$. In CPs, convergence rate $R_{c p}$ is $R_{c p}=\log \left[w_{a p c}(N / 2) / w_{a p c}(N)\right] / \log 2$.

Example 1. Consider DDE of second order [8]

$$
w^{\prime \prime}(t)=-\frac{1}{2} w(t)+\frac{1}{2} w(t-\pi), 0 \leq t \leq 8 \pi,
$$

with delay condition

$$
\mathrm{w}(\mathrm{t})=\sin \mathrm{t},-\pi \leq \mathrm{t} \leq 0,
$$

and initial condition

$$
\mathrm{w}(0)=0, \mathrm{w}^{\prime}(0)=1
$$

The analytical solution is $w(t)=\sin t$.

Example 2. Consider the following second-order DDE [1]

$$
w^{\prime \prime}(t)=-\frac{1}{2} w(t)+\frac{1}{2} w(t-\pi), t \in[0, \pi]
$$

with delay condition

$$
w(t)=1-\sin t,-\pi \leq t \leq 0,
$$

and initial condition

$$
w^{\prime}(0)=-1, w(0)=1
$$

The exact solution is $w(t)=1-\sin t$.

Example 3. Consider the following second-order DDE [1]

$$
w^{\prime \prime}(t)=w(t-\pi), t \in[0, \pi]
$$

with delay condition

$$
w(t)=\sin t,-\pi \leq t \leq 0,
$$

and initial condition

$$
w^{\prime}(0)=1, w(0)=0
$$

The exact solution is $w(t)=\sin t$.

Example 4. Consider DDE of second order as [36]

$$
w^{\prime \prime}(t)=-w(t)+w(t-1), 0 \leq t \leq 2,
$$

with delay condition

$$
w(t)=t^{2}+3 t+2,-1 \leq t \leq 0
$$

and initial condition

$$
w(0)=2, w^{\prime}(0)=0
$$

The exact solution is $w(t)=t^{2}+t-2+4 \cos t-\sin t, 0$ $\leq t \leq 1$.

Example 5. Consider the following second-order DDE [8]

$$
w^{\prime \prime}(t)=-\frac{\sin t}{2-\sin t} w(t-\pi), 0 \leq t \leq 8 \pi,
$$


TABle 1: $L_{c p}, R_{c}(N), M_{c p}$, and CPU time (seconds) for Example 1.

\begin{tabular}{ccccccc}
\hline $\mathrm{J}$ & $N=2^{J+1}$ & $L_{c p}$ & $R_{c}(N)$ & $M_{c p}$ & $R_{c}(N)$ & CPU time $(\mathrm{seconds})$ \\
\hline 1 & 4 & $3.97951 \times 10^{-03}$ & & $2.69531 \times 10^{-03}$ & & 0.00158 \\
2 & 8 & $1.04840 \times 10^{-03}$ & 1.9326 & $6.78403 \times 10^{-04}$ & 1.92440 & 0.00193 \\
3 & 16 & $2.68212 \times 10^{-04}$ & 1.9563 & $1.69886 \times 10^{-04}$ & 1.96674 & 0.00461 \\
4 & 32 & $6.77789 \times 10^{-05}$ & 1.9850 & $4.24894 \times 10^{-05}$ & 1.98446 & 0.01682 \\
5 & 64 & $1.70330 \times 10^{-05}$ & 1.9936 & $1.06234 \times 10^{-05}$ & 1.99250 & 0.06525 \\
6 & 128 & $4.26915 \times 10^{-06}$ & 1.9966 & $2.65593 \times 10^{-06}$ & 1.99631 & 0.20768 \\
7 & 256 & $1.06864 \times 10^{-06}$ & 2.0068 & $6.63892 \times 10^{-07}$ & 1.99817 & 0.81604 \\
8 & 512 & $2.67328 \times 10^{-07}$ & 1.9892 & $1.65997 \times 10^{-07}$ & 1.99909 & 1.79843 \\
9 & 1024 & $7.68531 \times 10^{-08}$ & 1.7977 & $4.14994 \times 10^{-08}$ & & 3.27512 \\
\hline
\end{tabular}

TABle 2: $L_{c p}, R_{c}(N), M_{c p}$, and CPU time (seconds) for Example 2.

\begin{tabular}{ccccccc}
\hline $\mathrm{J}$ & $N=2^{J+1}$ & $L_{c p}$ & $R_{c}(N)$ & $M_{c p}$ & $R_{c}(N)$ & CPU time $(\mathrm{seconds})$ \\
\hline 1 & 4 & $3.97951 \times 10^{-03}$ & & $2.69531 \times 10^{-03}$ & 0.00158 \\
2 & 8 & $1.04840 \times 10^{-03}$ & 1.9326 & $6.78403 \times 10^{-04}$ & 1.92440 & 0.00193 \\
3 & 16 & $2.68212 \times 10^{-04}$ & 1.9563 & $1.69886 \times 10^{-04}$ & 1.96674 & 0.00461 \\
4 & 32 & $6.77789 \times 10^{-05}$ & 1.9850 & $4.24894 \times 10^{-05}$ & 1.98446 & 0.01682 \\
5 & 64 & $1.70330 \times 10^{-05}$ & 1.9936 & $1.06234 \times 10^{-05}$ & 1.99250 & 0.06525 \\
6 & 128 & $4.26915 \times 10^{-06}$ & 1.9966 & $2.65593 \times 10^{-06}$ & 1.99631 & 0.20768 \\
7 & 256 & $1.06864 \times 10^{-06}$ & 2.0068 & $6.63892 \times 10^{-07}$ & 1.99817 & 0.81604 \\
8 & 512 & $2.67328 \times 10^{-07}$ & 1.9892 & $1.65997 \times 10^{-07}$ & 1.99909 & 1.79843 \\
9 & 1024 & $7.68531 \times 10^{-08}$ & 1.7977 & $4.14994 \times 10^{-08}$ & & 13.0245 \\
\hline
\end{tabular}

TABle 3: $L_{c p}, R_{c}(N), M_{c p}$, and CPU time (seconds) for Example 3.

\begin{tabular}{ccccccc}
\hline $\mathrm{J}$ & $N=2^{J+1}$ & $L_{c p}$ & $R_{c}(N)$ & $M_{c p}$ & $R_{c}(N)$ & CPU time (seconds) \\
\hline 1 & 4 & $4.26909 \times 10^{-03}$ & & $2.83925 \times 10^{-03}$ & 0.00140 & 0.00166 \\
2 & 8 & $1.13460 \times 10^{-03}$ & 1.9145 & $7.14201 \times 10^{-04}$ & 1.91174 & 0.00334 \\
3 & 16 & $2.91783 \times 10^{-04}$ & 1.9572 & $1.78823 \times 10^{-04}$ & 1.95921 & 0.01211 \\
4 & 32 & $7.39440 \times 10^{-05}$ & 1.9774 & $4.47228 \times 10^{-05}$ & 1.98039 & 0.03886 \\
5 & 64 & $1.86096 \times 10^{-05}$ & 1.9903 & $1.11817 \times 10^{-05}$ & 1.99038 & 0.14378 \\
6 & 128 & $4.66777 \times 10^{-06}$ & 1.9969 & $2.79551 \times 10^{-06}$ & 1.99524 & 0.53690 \\
7 & 256 & $1.16886 \times 10^{-06}$ & 2.0062 & $6.98881 \times 10^{-07}$ & 1.99763 & 1.99882 \\
9 & 512 & $2.92454 \times 10^{-07}$ & 1.9901 & $1.74720 \times 10^{-07}$ & 1.99940 & 11.0023 \\
\hline
\end{tabular}

with delay condition

$$
w(t)=2+\sin t-\pi \leq t \leq 0
$$

and initial condition

$$
w^{\prime}(0)=1, w(0)=2
$$

The exact solution is $w(t)=2+\sin t$.

\section{Discussion}

The second-order derivative in DDE is expressed as Haar function and the value of the first derivative is obtained by the process of integration. By applying the HCT, we obtain a system of linear equations by substituting CPs. The method of Gauss elimination is used for this system. Finally, by utilizing these coefficients, the solution at CPs is obtained. $L_{c p}$ and $M_{c p}$ errors for different number of CPs are given in Tables. 
TABLE 4: $L_{c p}, R_{c}(N), M_{c p}$, and CPU time (seconds) for Example 4.

\begin{tabular}{ccccccc}
\hline $\mathrm{J}$ & $N=2^{J+1}$ & $L_{c p}$ & $R_{c}(N)$ & $M_{c p}$ & $R_{c}(N)$ & CPU time $(\mathrm{seconds})$ \\
\hline 1 & 4 & $7.24881 \times 10^{-03}$ & & $4.60001 \times 10^{-03}$ & 0.00197 & 0.00277 \\
2 & 8 & $1.95251 \times 10^{-03}$ & 1.8925 & $1.14978 \times 10^{-03}$ & 2.01260 & 0.04996 \\
3 & 16 & $5.05791 \times 10^{-04}$ & 1.9491 & $2.87450 \times 10^{-04}$ & 1.98991 & 0.01505 \\
4 & 32 & $1.28646 \times 10^{-04}$ & 1.9801 & $7.18631 \times 10^{-05}$ & 1.99899 & 0.05394 \\
5 & 64 & $3.24351 \times 10^{-05}$ & 1.9821 & $1.79658 \times 10^{-05}$ & 2.00402 & 0.19726 \\
6 & 128 & $8.14288 \times 10^{-06}$ & 1.9929 & $4.49145 \times 10^{-06}$ & 1.99517 & 0.77262 \\
7 & 256 & $2.03997 \times 10^{-06}$ & 2.0035 & $1.12286 \times 10^{-06}$ & 2.00321 & 3.07790 \\
8 & 512 & $5.10526 \times 10^{-07}$ & 1.9929 & $2.80716 \times 10^{-07}$ & 2.00000 & 1.99794 \\
9 & 1024 & $1.27698 \times 10^{-07}$ & 2.0057 & $7.01790 \times 10^{-08}$ & & 12.3348 \\
\hline
\end{tabular}

TABle 5: $L_{c p}, R_{c}(N), M_{c p}$, and CPU time (seconds) for Example 5.

\begin{tabular}{ccccccc}
\hline $\mathrm{J}$ & $N=2^{J+1}$ & $L_{c p}$ & $R_{c}(N)$ & $M_{c p}$ & $R_{c}(N)$ & CPU time $(\mathrm{seconds})$ \\
\hline 1 & 4 & $4.26909 \times 10^{-03}$ & & $2.83925 \times 10^{-03}$ & 0.00196 & 0.00301 \\
2 & 8 & $1.13460 \times 10^{-03}$ & 1.9145 & $7.14201 \times 10^{-04}$ & 1.9868 & 0.00947 \\
3 & 16 & $2.91783 \times 10^{-04}$ & 1.9572 & $1.78823 \times 10^{-04}$ & 2.0040 & 0.02115 \\
4 & 32 & $7.39440 \times 10^{-05}$ & 1.9774 & $4.47228 \times 10^{-05}$ & 1.9935 & 0.06661 \\
5 & 64 & $1.86096 \times 10^{-05}$ & 1.9903 & $1.11817 \times 10^{-05}$ & 2.0097 & 0.25637 \\
6 & 128 & $4.66777 \times 10^{-06}$ & 1.9969 & $2.79551 \times 10^{-06}$ & 1.9922 & 1.03078 \\
7 & 256 & $1.16886 \times 10^{-06}$ & 2.0062 & $6.98881 \times 10^{-07}$ & 1.9990 & 4.09742 \\
8 & 512 & $2.92454 \times 10^{-07}$ & 1.9901 & $1.74720 \times 10^{-07}$ & 2.0041 & 1.9967 \\
9 & 1024 & $7.31435 \times 10^{-08}$ & 1.9980 & $4.36801 \times 10^{-08}$ & & 16.4587 \\
\hline
\end{tabular}

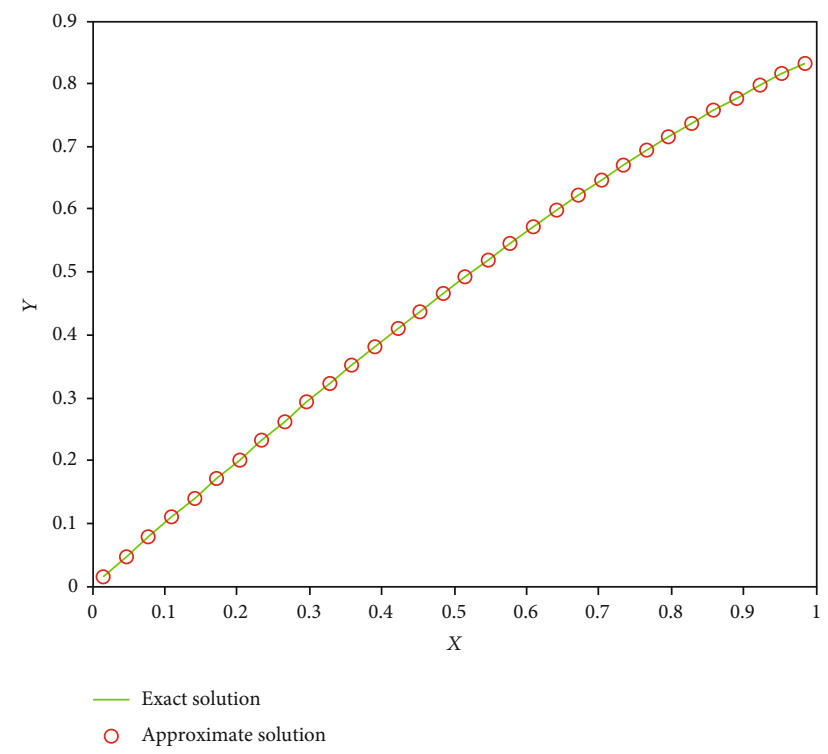

FIGURE 1: Comparison of both exact and approximate solution for 32 CPs for Example 1.

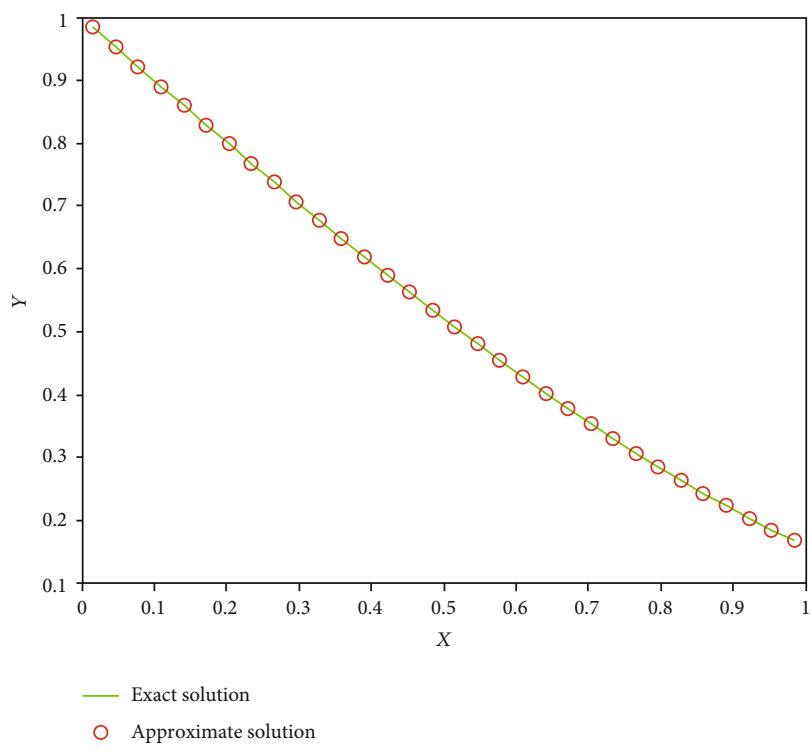

FIgURE 2: Comparison of both exact and approximate solution for 32 CPs for Example 2. 


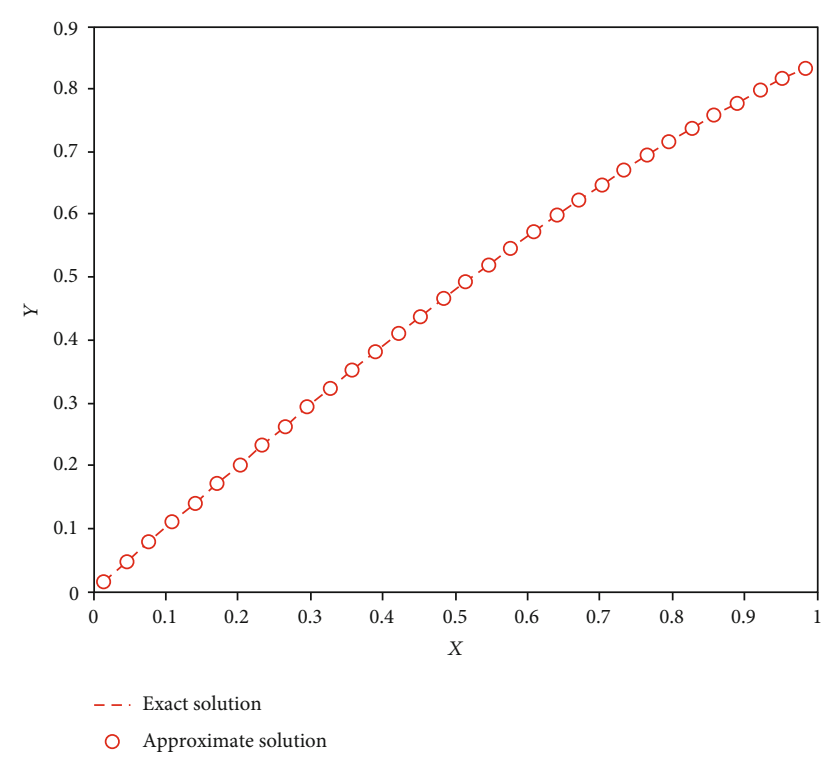

Figure 3: Comparison of both exact and approximate solution for 32 CPs for Example 3.

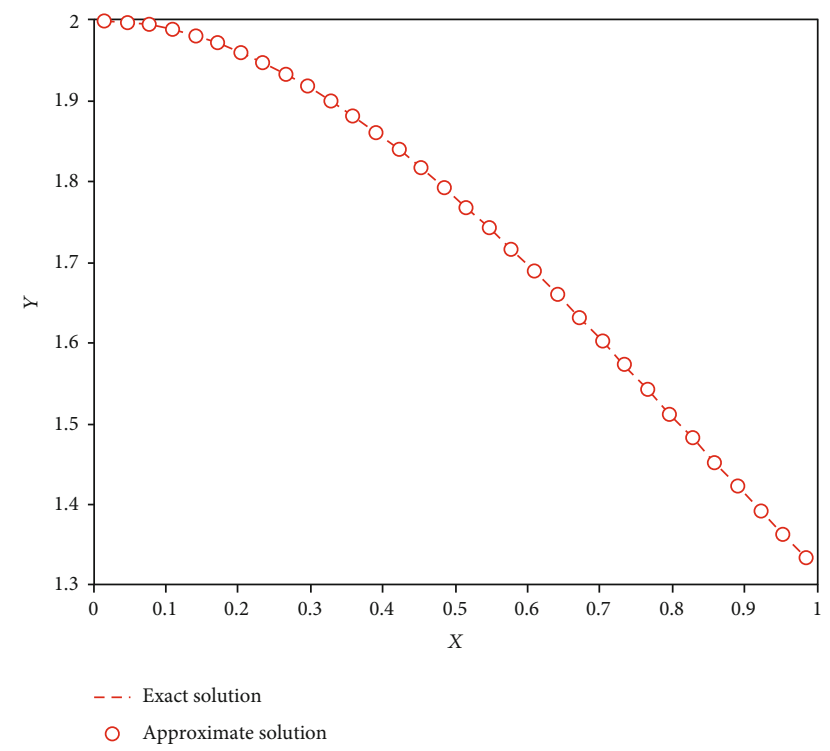

FIGURE 4: Comparison of both exact and approximate solution for 32 CPs for Example 4.

$R_{c}(N)$ and CPU time (seconds) are also reported in tables for each example. For Example 1, $L_{c p}$ and $M_{c p}$ errors for different number of CPs are shown in Table 1. Table 2 shows the errors for different number of CPs for Example 2, Table 3 represents errors for different number of CPs for Example 3, Table 4 shows the errors for different number of CPs for Example 4, and Table 5 shows the errors for different number of CPs for Example 5. All errors are decreased by taking more CPs. $R_{c p}$ is determined which is nearly equal to 2 , supporting the results shown in [37] by Majak et al. The comparison of both numerical and analytical solution at $N=32 \mathrm{CPs}$ is also shown in figures. Figure 1 represents the comparison of approximate and exact solution for Example 1, Figure 2 represents the comparison of approximate and exact solution for

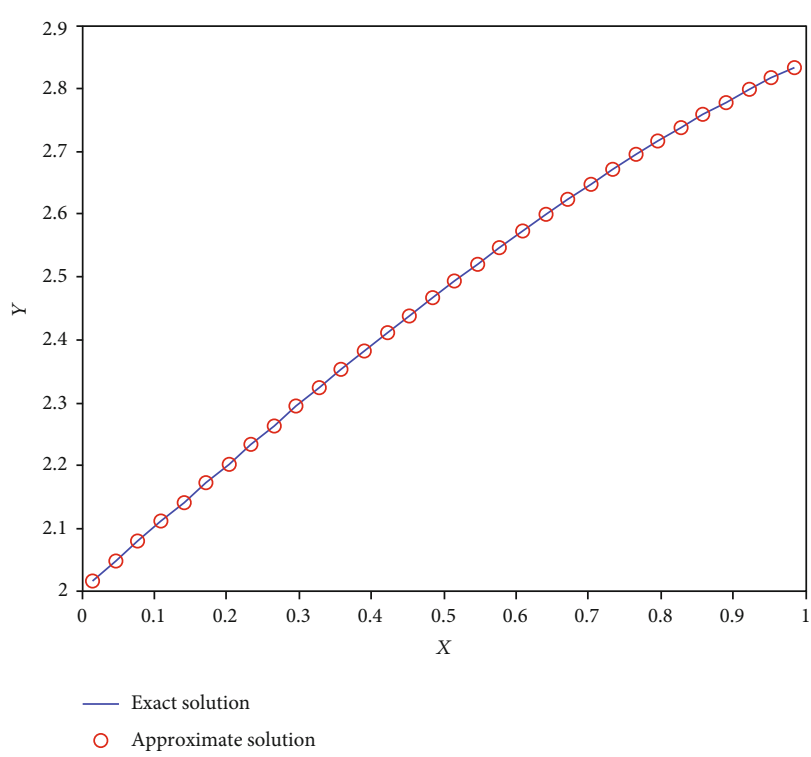

Figure 5: Comparison of both exact and approximate solution for 32 CPs for Example 5.

Example 2, Figure 3 represents the comparison of approximate and exact solution for Example 3, Figure 4 represents the comparison of approximate and exact solution for Example 4, and Figure 5 represents the comparison of exact and approximate solution for Example 5.

\section{Conclusion}

HCT scheme is devoted for the solution of second-order DDEs to deal with the experimentation of IIoT. The Haar technique is applied to linear DDEs for dealing with the experimentation of the Internet of Industrial Things. The Matlab software is utilized to experiment the Haar wavelet technique with the examples, and the numerical solution is compared with the exact solution. We compare the obtained solution with the exact solution and also we compute the $L_{c p}$ and $M_{c p}$ errors to show the accuracy of the Haar wavelet technique. We give some test problems for the illustration of our results. The experimental rate $R_{c}(N)$ of convergence for different number of CPs is also calculated which is approximately equal to 2 . The results show that HCT is efficient for solving second-order DDEs. Our future work addresses to overcome the limitation of this study. Moreover, we will apply this technique to high order DDEs and system of DDEs.

\section{Data Availability}

No data is available.

\section{Conflicts of Interest}

There is no conflicting interest. 


\section{References}

[1] H. Y. Seong and Z. A. Majid, "Solving second order delay differential equations using direct two-point block method," Ain Shams Engineering Journal, vol. 8, no. 1, pp. 59-66, 2017.

[2] S. Sedaghat, Y. Ordokhani, and M. Dehghan, "Numerical solution of the delay differential equations of pantograph type via Chebyshev polynomials," Communications in Nonlinear Science and Numerical Simulation, vol. 17, no. 12, pp. 48154830, 2012.

[3] S. Nazir, Y. Ali, N. Ullah, and I. García-Magariño, "Internet of things for healthcare using effects of mobile computing: a systematic literature review," Wireless Communications and Mobile Computing, page, vol. 2019, article 5931315, pp. 1-20, 2019.

[4] R. Amin, S. Nazir, and I. García-Magariño, “A collocation method for numerical solution of nonlinear delay integrodifferential equations for wireless sensor network and internet of things," Sensor, vol. 20, no. 7, article 1962, 2020.

[5] M. A. Ibrahim, A. El-Safty, and S. M. Abo-Hasha, " $2 h$-Step spline method for the solution of delay differential equations," Computers \& Mathematics with Applications, vol. 29, no. 8, pp. 1-6, 1995.

[6] J. O. Ehigie, S. A. Okunuga, and A. B. Sofoluwe, "3-point block methods for direct integration of general second-order ordinary differential equations," Advances in Numerical Analysis, vol. 2011, Article ID 513148, 14 pages, 2011.

[7] M. Ghasemi and M. Tavassoli Kajani, "Numerical solutions of time-varying delay system by chebyshev wavlets," Applied Mathematical Modelling, vol. 35, pp. 5235-5244, 2011.

[8] S. Z. Ahmad, F. Ismail, and N. Senu, "Solving oscillatory delay differential equations using block hybrid methods," Journal of Mathematics, vol. 2018, Article ID 2960237, 7 pages, 2018.

[9] S. A. Okunuga and J. Ehigie, "A new derivation of continuous collocation multistep methods using power series as basis function," Journal of the Nigerian Association of Mathematical Physics, vol. 3, pp. 43-50, 2009.

[10] R. L. Brown, "Some characteristics of implicit multistep multiderivative integration formulas," SIAM Journal on Numerical Analysis, vol. 14, pp. 982-993, 1977.

[11] F. Ismail, L. K. Yap, and O. Mohamad, "Explicit and implicit 3point block methods for solving special second order ordinary differential equations directly," International Journal of Mathematical Analysis, vol. 3, no. 5, pp. 239-254, 2009.

[12] J. O. Ehigie, S. A. Okunuga, and A. B. Sofoluwe, "On generalized 2-step continuous linear multistep method of hybrid type for the integration of second order ordinary differential equations," Archives of Applied Science Research, vol. 2, pp. 362$372,2010$.

[13] J. B. Rosser, "A runge-kutta for all seasons," SIAM Review, vol. 9, no. 3, pp. 417-452, 1967.

[14] W. L. Chen and Y. P. Shi, "Shift walsh matrix and delay differential equations," IEEE Transactions on Automatic Control, vol. 23, pp. 265-280, 1978.

[15] H. J. Oberle and H. J. Pesh, "Numerical treatment of delay differential equations by hermite interpolation," Numerische Mathematik, vol. 37, no. 2, pp. 235-255, 1981.

[16] H. Arnt, "Numerical solution of retarded initial-value problems: Local and global error and stepsize control," Numerische Mathematik, vol. 43, no. 3, pp. 343-360, 1984.
[17] A. Bellen, "One-step collocation for delay differential equations," Journal of Computational and Applied Mathematics, vol. 10, no. 3, pp. 275-283, 1984.

[18] H. C. San, Z. A. Majid, and M. Othman, "Solving delay differential equations using coupled block method," in 2011 Fourth International Conference on Modeling, Simulation and Applied Optimization, p. 11, Kuala Lumpur, Malaysia, April 2011.

[19] Z. A. Majid, N. A. Azmi, and M. Suleiman, "Solving second order ordinary differential equations using two point four step direct implicit block method," European Journal of Scientific Research, vol. 31, pp. 29-36, 2009.

[20] T. Allahviranloo, N. Ahmady, and E. Ahmady, "Numerical solution of fuzzy differential equations by predictor-corrector method," Information Sciences, vol. 177, no. 7, pp. 16331647, 2007.

[21] S. Abbasbandy and T. Allahviranloo, "Numerical solutions of fuzzy differential equations by taylor method," Computational Methods in Applied Mathematics, vol. 2, no. 2, pp. 113-124, 2002.

[22] S. L. Chang and L. A. Zadeh, "On fuzzy mapping and control," IEEE Transactions on Systems, Man, and Cybernetics, vol. 2, pp. 30-34, 1972.

[23] H. Jafari, M. Saeidy, and D. Baleanu, "The variational iteration method for solving n-th order fuzzy differential equations," Central European Journal of Physics, vol. 10, no. 1, pp. 76-85, 2012.

[24] Z. M. Odibat, "A study on the convergence of variational iteration method," Mathematical and Computer Modelling, vol. 51, no. 9-10, pp. 1181-1192, 2010.

[25] C. Hwang and M. Y. Chen, "Analysis of time-delay systems using the Galerkin method," International Journal of Control, vol. 44, no. 3, pp. 847-866, 1986.

[26] W. Liu, G. Huang, A. Zheng, and J. Liu, "Research on the optimization of iiot data processing latency," Computer Communications, vol. 151, pp. 290-298, 2020.

[27] R. Sahal, J. G. Breslin, and M. I. Ali, "Big data and stream processing platforms for industry 4.0 requirements mapping for a predictive maintenance use case," Journal of Manufacturing Systems, vol. 54, pp. 138-151, 2020.

[28] W. Z. Khan, M. H. Rehman, H. M. Zangoti, M. K. Afzal, N. Armi, and K. Salah, "Industrial internet of things: recent advances, enabling technologies and open challenges," Computers and Electrical Engineering, vol. 81, p. 106522, 2020.

[29] N. Gulati and P. D. Kaur, "Towards socially enabled internet of industrial things: architecture, semantic model and relationship management," Ad Hoc Networks, vol. 91, article 101869, 2019.

[30] M. M. Khashan, R. Amin, and M. I. Syam, "A new algorithm for fractional riccati type differential equations by using haar wavelet," Mathematics, vol. 7, no. 6, p. 545, 2019.

[31] S. Nazir, S. Shahzad, R. Wirza et al., "Birthmark based identification of software piracy using haar wavelet," Mathematics and Computers in Simulation, vol. 166, pp. 144-154, 2019.

[32] R. Amin, S. Nazir, and I. G. Magariño, "Efficient sustainable algorithm for numerical solution of nonlinear delay fredholm-volterra integral equations via haar wavelet for dense sensor networks in emerging telecommunications," Transactions on Emerging Telecommunications Technologies, no. article e3877, 2020.

[33] T. Abdeljawad, R. Amin, K. Shah, Q. Al-Mdallal, and F. Jarad, "Efficient sustainable algorithm for numerical solutions of 
systems of fractional order differential equations by haar wavelet collocation method," Alexandria Engineering Journal, vol. 59, no. 4, pp. 2391-2400, 2020.

[34] R. Amin, K. Shah, M. Asif, I. Khan, and F. Ullah, "An efficient algorithm for numerical solution of fractional integrodifferential equations via Haar wavelet," Journal of Computational and Applied Mathematics, vol. 381, p. 113028, 2021.

[35] I. Aziz and R. Amin, "Numerical solution of a class of delay differential and delay partial differential equations via haar wavelet," Applied Mathematical Modelling, vol. 40, no. 23-24, pp. 10286-10299, 2016.

[36] H. M. Radzi, Z. A. Majid, F. Ismail, and M. Suleiman, "Two and three point one-step block methods for solving delay differential equations," Journal of Quality Measurement and Analysis, vol. 8, pp. 29-41, 2012.

[37] J. Majak, B. S. Shvartsman, M. Kirs, M. Pohlak, and H. Herranen, "Convergence theorem for the Haar wavelet based discretization method," Composite Structures, vol. 126, pp. 227-232, 2015. 